\title{
Avaliação da aplicabilidade de uma cepa probiótica de Saccharomyces cerevisiae em barras de cereais
}

\author{
Evaluation of the applicability of a probiotic strain of Saccharomyces cerevisiae in \\ cereal bars
}

\author{
Drielly Dayanne Monteiro dos Santos Baliza ${ }^{1 *}$ (i), Juliana Fonseca Moreira da Silva', Raphael Sanzio Pimenta ${ }^{1}$ \\ ${ }^{1}$ Fundação Universidade Federal do Tocantins, Laboratório de Microbiologia Geral e Aplicada, Palmas/TO - Brasil

\section{*Corresponding Author} \\ Drielly Dayanne Monteiro dos Santos Baliza, Fundação Universidade Federal do Tocantins, Laboratório de Microbiologia Geral e Aplicada, Quadra \\ 109 Norte, Av. NS-15, ALCNO-14, Plano Diretor Norte, CEP: 77001-090, Palmas/TO - Brasil, e-mail: drielly.dayanne@gmail.com
}

Cite as: Evaluation of the applicability of a probiotic strain of Saccharomyces cerevisiae in cereal bars. Braz. J. Food Technol., v. 21, e2017148, 2018.

Received: Sept. 06, 2017; Accepted: Apr. 30, 2018

\section{Resumo}

O objetivo deste estudo foi avaliar a utilização de uma levedura probiótica na produção de barra de cereais, contribuindo para a produção de um alimento funcional inovador. Uma mistura de chocolate inoculada com $8 \log _{10}$ células $/ \mathrm{mL}$ viáveis da levedura foi inserida sobre a superfície da barra de cereais. Foram verificados os parâmetros físicos, químicos e sensoriais, e quantificado o número de células durante o período de armazenamento, até a morte celular da levedura. Os resultados demonstraram que a presença da levedura não afetou negativamente as propriedades físicas e químicas da barra de cereais. Nos parâmetros avaliados sensorialmente, não foi observada preferência em relação às barras sem levedura probiótica. A levedura se manteve viva $\left(10^{4}\right.$ células $\left./ g\right)$ por 45 dias.

Palavras-chave: Viabilidade microbiana; Tecnologia de alimentos; Análise sensorial; Composição centesimal; Chocolate; Levedura.

\section{Abstract}

The objective of this study was to evaluate the use of a probiotic yeast in the production of a cereal bar, contributing to the production of an innovative functional food. For this, a chocolate mixture inoculated with $8 \log _{10}$ viable yeast cells was spread onto the surface of the cereal bar. The physical, chemical and sensory parameters of the probiotic cereal bar were verified and the number of cells quantified up to the death of the yeast cells. The results showed that the presence of the yeast did not negatively affect the physical and chemical properties of the cereal bar. No preference was observed in relation to the bars without probiotic yeast for the sensorial parameters evaluated. The yeast remained alive $\left(10^{4} \mathrm{cells} / \mathrm{g}\right)$ for 45 days.

Keywords: Microbial viability; Food technology; Sensory analysis; Proximate composition; Chocolate; Yeast.

\section{Introdução}

Os alimentos funcionais são definidos como alimentos que fornecem benefícios além dos nutricionais básicos. Estes benefícios são provenientes de compostos biologicamente ativos, que podem ser desde micro-organismos a proteínas, vitaminas, dentre outras substâncias (LAU et al., 2017). A estes micro-organismos, é designado o termo probiótico, e são definidos pela Food and Agriculture Association of the United Nations (FAO) e Organização Mundial de Saúde (OMS) como micro-organismos vivos (bactérias e leveduras), os quais, ao serem ingeridos em quantidade suficiente, promovem benefícios à saúde do hospedeiro
(COOK et al., 2012). No entanto, o potencial probiótico ou benéfico de leveduras geralmente é ignorado (CHEN et al., 2010). Atualmente, a levedura Saccharomyces boulardii, utilizada como probiótico, é praticamente a única espécie comercializada (KENNY et al., 2011).

Dentre as características dos probióticos, está a estimulação dos mecanismos imunitários e não imunitários da mucosa, através de um antagonismo/concorrência com os patógenos potenciais (WGO, 2008), a ativação de macrófagos locais e a modulação da produção de IgA, promovendo mudanças nos perfis das citocinas pró e anti-inflamatórias 
e/ou modulação de resposta a antígenos alimentares (KABEERDOSS et al., 2011). Alguns produzem certas vitaminas, como biotina, ácido fólico, ácido nicotínico e tiamina, proporcionando uma suplementação vitamínica ao hospedeiro (VANDENPLAS et al., 2015) e lactase, contribuindo para o alívio de cólicas abdominais, náusea e inchaço em intolerantes à lactose (DE VRESE et al., 2001; RAO et al., 2012). Possuem ação na regulação do trânsito gastrointestinal, reduzindo inchaço ou produção de gases, além de melhorar a absorção de íons pelas células epiteliais do intestino (BORTHAKUR et al., 2008). Para que esses benefícios sejam manifestos, o probiótico tem de ser capaz de sobreviver à passagem pelo aparelho digestivo e resistir ao ácido e à bile, e proliferar no intestino (VANDENPLAS et al., 2015).

O impacto de probióticos na saúde humana tem direcionado o desenvolvimento econômico de produtos que os contêm, compreendendo entre $60 \%$ a $70 \%$ de todo o mercado de alimentos funcionais (TRIPATHI; GIRI, 2014). Geralmente, os probióticos são comercializados suplementando alimentos lácteos ou em cápsulas medicamentosas, indicadas para recomposição da microbiota intestinal, sendo, em sua grande maioria, utilizados micro-organismos dos gêneros Lactobacillus spp. e Bifidobacterium spp. (RAUD, 2008; SHORI, 2015). Apesar de haver outros tipos de alimentos probióticos, como sucos de frutas e produtos à base de chocolate, estes representam uma pequena parcela do mercado (DE PRISCO; MAURIELLO, 2016). No entanto, os alimentos probióticos não lácteos fornecem o acesso a essa categoria de alimento saudável por pessoas que não apreciam leite e seus derivados, ou a intolerantes à lactose e veganos, pessoas com restrição a alimentos contendo colesterol ou que sigam dieta específica (GAWKOWSKI; CHIKINDAS, 2013).

A Saccharomyces cerevisiae possui semelhanças genéticas e diferenças metabólicas em relação à Saccharomyces boulardii (KENNY et al., 2011), além do status de Geralmente Considerado como Seguro (GRAS) pela Food and Drug Administration (FDA). Estudos demonstraram que algumas linhagens possuem propriedades probióticas (KOVACS; BERK, 2000; VIEIRA et al., 2013), como a Saccharomyces cerevisiae UFMG 905, isolada a partir de destilaria de cachaça no Estado de Minas Gerais, identificada e classificada como S. cerevisiae, de acordo com os métodos de Kurtzman e Fell (1998) e Yarrow (1998), com identidade confirmada através do programa computacional YEASTCOMPARE (CIRIELLO; LACHANCE 2001). Dessa forma, o objetivo deste trabalho foi avaliar a utilização de uma levedura probiótica em barras de cereais prontas para o consumo, avaliando-se os parâmetros físico-químicos e sensoriais, e a viabilidade da levedura durante o período de armazenamento.

\section{Material e métodos}

A levedura Saccharomyces cerevisiae UFMG 905 foi isolada de uma destilaria de cachaça no Estado de Minas Gerais e pertence à Coleção de Micro-organismos e Células da Universidade Federal de Minas Gerais. As células foram obtidas por cultura em ágar YM (2\% de glicose, $0,5 \%$ de peptona, $0,3 \%$ de extrato de malte, $0,3 \%$ de extrato de levedura e $2 \%$ de ágar) incubada a $25^{\circ} \mathrm{C}$ por 48 h. As colônias foram ressuspensas em solução salina $0,85 \%$. A concentração celular foi determinada utilizando um hemocitômetro e ajustada para $8 \log _{10}$ células $/ \mathrm{mL}$ em um volume final de $32 \mathrm{~mL}$.

A incorporação da levedura nas barras de cereais se deu na forma de células livres adicionadas a $120 \mathrm{~g}$ de chocolate comercial meio amargo (53\% cacau), fundido a $40^{\circ} \mathrm{C}$, e o chocolate inoculado foi depositado sobre a superfície de barras de cereais comerciais, em condições de assepsia. A concentração de cacau e a temperatura foram escolhidas após testes de tentativa e erro, quanto à homogeneização do micro-organismo no alimento, e verificação da viabilidade celular. Foram utilizadas 117 barras de cereais de $20 \mathrm{~g}$, das quais 47 barras receberam a mistura de levedura e chocolate, 35 barras de cereais receberam apenas chocolate (controle) e 35 barras já foram adquiridas com chocolate próprio da marca (comercial). As barras de cereais adquiridas possuíam o prazo de validade de 10 meses. Após a solidificação do chocolate, as barras de cereais foram cortadas em tamanhos de aproximadamente $10 \mathrm{~g}$, embaladas individualmente em sacos de polietileno que foram selados em seladora mecânica. Todas as barras de cereais (inoculada, controle e comercial) foram acondicionadas nas embalagens individuais e armazenadas sob as mesmas condições, em temperatura ambiente $\left(25^{\circ} \mathrm{C}\right)$. O experimento foi realizado em triplicata.

A viabilidade de S. cerevisiae UFMG 905 foi determinada ao final de 0, 7, 14, 30, 45 e 60 dias de armazenamento, a $25{ }^{\circ} \mathrm{C}$. O procedimento realizado consistiu em retirar porções de $1 \mathrm{~g}$ da barra de cereais descompactada manualmente, em condições de assepsia, e diluir em $9 \mathrm{~mL}$ de solução salina 0,85\%. Em seguida, $1 \mathrm{~mL}$ da diluição foi transferida para um tubo estéril de $1,5 \mathrm{~mL}$, procedendo com a semeadura em superfície em placa de Petri contendo ágar YM, por meio de um equipamento de inoculação automática de placas (Spiral Plater, IOL instruments ${ }^{\circledR}$ ). As placas foram incubadas a $25^{\circ} \mathrm{C}$ por 48 h. Após a incubação, o número de células foi determinado por contador automático de colônias (Flash \& Go, IOL instruments ${ }^{\circledR}$ ) e os resultados expressos em logaritmo decimal de unidade formadora de colônias por grama $\left(\log _{10} U \mathrm{UFC} / \mathrm{g}\right)$. As análises foram realizadas em triplicata.

As análises da composição das barras de cereais inoculadas com a levedura foram realizadas de acordo com 
os métodos do Instituto Adolfo Lutz (IAL, 2008), após duas semanas da análise de viabilidade celular e confirmação da resistência microbiana ao chocolate utilizado. Todas as análises foram realizadas em triplicata. O teor de proteínas foi determinado pelo método de Kjeldahl (nitrogênio total), utilizando 5,75 como fator de conversão (método 036/IV) (BRASIL, 2003); cinzas, em mufla a $550{ }^{\circ} \mathrm{C}$ (método 018/IV); umidade, em estufa a $105^{\circ} \mathrm{C}$ até peso constante (método 012/IV), e lipídios, por extração em Soxhlet, utilizando éter de petróleo (método 032/IV).

A confirmação da segurança microbiológica para a análise sensorial foi realizada após três dias da preparação das amostras pela determinação em triplicata do Número Mais Provável de Coliformes a $45^{\circ} \mathrm{C}$ e da presença de Salmonella sp. em $25 \mathrm{~g}$, de acordo com as instruções do Manual de Métodos de Análise Microbiológica de Alimentos e Água (SILVA et al., 2010).

A avaliação sensorial foi realizada por 70 julgadores não treinados, após aprovação pelo Comitê de Ética em Pesquisa com Seres Humanos da Universidade Federal do Tocantins (parecer n. ${ }^{\circ}$ 1.624.709), no Laboratório de Análise Sensorial da Universidade Federal do Tocantins, utilizando o teste afetivo de aceitação por escala hedônica de 9 pontos, em que 9 = gostei muitíssimo e 1 = desgostei muitíssimo (DUTCOSKY, 2013). Foram oferecidas três amostras de aproximadamente $10 \mathrm{~g}$ para cada julgador: uma amostra controle (barra de cereais com chocolate 53\% cacau, mas sem o micro-organismo); uma amostra da barra de cereais probiótica (chocolate 53\% cacau inoculado com a levedura), e uma amostra de barra de cereais comercial líder de mercado (barra de cereais com o chocolate da própria marca). Cada amostra foi codificada com três algarismos aleatórios e o teste foi conduzido sob luz branca, equivalente à luz do dia, em cabines individuas, sem ruídos. As amostras foram apresentadas em temperatura ambiente juntamente com água e biscoito de água e sal, para neutralizar o paladar entre o consumo das amostras. A avaliação foi realizada após cinco dias de armazenamento em temperatura ambiente $\left(25^{\circ} \mathrm{C}\right) \mathrm{e}$ os parâmetros avaliados foram aparência, aroma, textura e sabor. Uma escala estruturada de cinco pontos foi utilizada para verificação da intenção de compra, em que 5 = certamente compraria e 1 = certamente não compraria (DUTCOSKY, 2013). O índice de aceitabilidade (IA) dos produtos foi calculado pela relação entre a nota média (representada por x) e a nota máxima (representada por y) que o produto recebeu, conforme o cálculo proposto por Teixeira et al. (1987): IA (\%) = [(x/y) x 100].

Os resultados foram submetidos à Análise de Variância (ANOVA) por meio do programa Assistat 7.7 beta, com delineamento inteiramente casualizado, seguida pelo teste de Tukey $(p \leq 0,05)$. Os resultados foram expressos como média \pm desvio padrão.

\section{Resultados e discussão}

A análise físico-química da barra de cereais inoculada com o micro-organismo probiótico demonstrou que a presença da levedura na cobertura de chocolate da barra de cereais não ocasionou alterações nos parâmetros físico-químicos. Os resultados dos teores de lipídios, proteínas e cinzas (sais minerais) nas barras de cereais inoculadas foi de 10,24\%,5,38\% e 1,20\%, respectivamente. Esses valores estão próximos aos encontrados por Sema-Cock et al. (2015), em barras de cereais inoculadas com Weissella confusa $(16,7 \%$ de lipídios, 5,83\% de proteínas e $2 \%$ de cinzas), e por Bampi et al. (2016), em barras de cereais inoculadas com Lactobacillus acidophilus e Bifidobacterium animalis subsp. lactis (3,3\% de lipídios e 7,1\% de proteínas). Não foram encontrados na literatura dados de composição centesimal de barras de cereais inoculadas com leveduras probióticas.

O limite exigido pela legislação brasileira quanto ao teor de umidade em produtos à base de cereais (máximo $15 \%)$ foi atendido (8,9\% de umidade) (BRASIL, 2005). De acordo com Guimarães e Silva (2009), teores elevados de umidade favorecem o escurecimento enzimático e o crescimento microbiano, influenciando negativamente a qualidade sensorial do produto.

A Tabela 1 apresenta a viabilidade da levedura S. cerevisiae UFMG 905 nas barras de cereais. Após o processamento, houve um decréscimo de $1 \mathrm{log}$ UFC/g em relação à concentração inicialmente inoculada na cobertura de chocolate (8 log UFC/g). Essa redução pode estar relacionada à pressão osmótica resultante da concentração do chocolate ao qual a levedura foi incorporada, além de outros compostos resultantes da peroxidação lipídica desse chocolate, causando danos ao DNA dos micro-organismos (TRIPATHI; GIRI, 2014).

Durante a contagem de células, a levedura manteve-se estável com concentração de 107 UFC/g (7 log UFC/g) por 14 dias. Aos 30 dias de armazenamento, houve perda de $1 \mathrm{log}$ UFC/g, atingindo $10^{4} \mathrm{UFC} / \mathrm{g}$ (4 log UFC/g), aos 45 dias. Aos 60 dias de armazenamento, não foi detectada presença de células viáveis no produto. Essa

Tabela 1. Viabilidade celular da levedura S. cerevisiae UFMG 905 (média \pm desvio padrão) na barra de cereais durante 45 dias de armazenamento.

\begin{tabular}{ccc}
$\begin{array}{c}\text { Tempo } \\
\text { (dias) }\end{array}$ & $\begin{array}{c}\text { Viabilidade } \\
\left.\mathbf{( L o g}_{10} \mathbf{U F C} / \mathbf{g}\right)\end{array}$ & $\begin{array}{c}\text { Desvio padrão } \\
0\end{array} 7^{\mathrm{a}}$ \\
7 & $7,3^{\mathrm{a}}$ & 0,03 \\
14 & $7,2^{\mathrm{a}}$ & 0,01 \\
30 & $6,6^{\mathrm{b}}$ & 0,03 \\
45 & $4,9^{\mathrm{c}}$ & 0,05 \\
\hline
\end{tabular}

Médias seguidas de letras iguais não diferem estatisticamente entre si pelo teste de Tukey a $5 \%$ de probabilidade. 
perda da viabilidade possivelmente está relacionada à formação de compostos com atividade antimicrobiana, como epoxi, hidroxi e ceto-triol (BRUDZYNSKI, 2007), resultantes de reações de degradação do chocolate através da oxidação de fitoesteróis (BOTELHO et al., 2014). Sema-Cock et al. (2015) aplicaram chocolate branco como cobertura nas barras de cereais contendo a bactéria láctica Weissella confusa e verificaram contagem acima de $10^{7}$ UFC/g após o processamento; no entanto, os autores não avaliaram a viabilidade durante armazenamento.

Segundo a legislação brasileira, para que um alimento tenha efeito probiótico, é necessário o consumo diário entre $10^{8}$ a $10^{9}$ micro-organismos viáveis (BRASIL, 2008). Para que as barras de cereais deste estudo apresentem alegação funcional, deve ser considerado o consumo de $20 \mathrm{~g}$ na concentração de $7 \mathrm{log}$ UFC/g. No entanto, levando em consideração o prazo de validade das barras de cereais comercializadas, outras formas de incorporação desta levedura probiótica devem ser estudadas, visando ao aumento da viabilidade nesta matriz alimentícia.

O chocolate é uma boa matriz para a incorporação de micro-organismos probióticos (POSSEMIERS et al., 2010), mas a temperatura empregada para sua obtenção na forma líquida pode causar a morte do micro-organismo. A temperatura utilizada para fundir o chocolate, neste estudo, foi de $40{ }^{\circ} \mathrm{C}$, na qual foi verificada tolerância significativa da levedura S. cerevisiae UFMG 905. Apesar de utilizarem temperatura relativamente baixa $\left(40{ }^{\circ} \mathrm{C}\right)$, Raymond e Champagne (2015) relataram perdas de aproximadamente 0,2 log por g de células viáveis da bactéria Lactobacillus rhamnosus, sugerindo a microencapsulação como uma alternativa de proteção, a fim de se obterem melhores resultados. No entanto, ao utilizar esse tipo de proteção, Bastos et al. (2014) obtiveram 3 log abaixo do inicialmente aplicado (10 11 UFC/g) às barras e encontraram concentração celular acima de $6 \mathrm{log}$ UFC/g por apenas quatro semanas, tempo inferior ao verificado nesta pesquisa.

De acordo com Tournade et al. (2005), alguns micro-organismos podem permanecer viáveis por vários meses de armazenamento à temperatura ambiente, desde que os açúcares presentes no produto não possam ser metabolizados. As espécies de Saccharomyces cerevisiae são capazes de assimilar várias fontes de carbono (como glicose, frutose e manose) (GANCEDO et al., 1982; CARLSON, 1999; SÁ, 2012), prejudicando, possivelmente, a viabilidade da levedura na cobertura das barras de cereais.

Os resultados da análise microbiológica encontram-se na Tabela 2. As barras de cereais desenvolvidas apresentaram-se aptas para consumo de acordo com os padrões recomendados pela Agência Nacional de Vigilância Sanitária (BRASIL, 2001).

O resultado da avaliação sensorial encontra-se na Tabela 3. Apenas a amostra controle obteve média em torno de 8 (gostei muito), atribuída ao parâmetro aparência.
Nos demais parâmetros, todas as amostras receberam nota em torno de 7 (gostei moderadamente), não sendo detectada diferença significativa $(p>0,05)$ entre as barras de cereais controle, probiótica e comercial, em todos os atributos avaliados.

Bastos et al. (2014) avaliaram a adição da levedura Saccharomyces boulardii e da bactéria Lactobacillus acidophilus em barras de cereais na forma liofilizada e microencapsulada, e observaram que ambos os micro-organismos não afetaram a qualidade sensorial e estrutural das barras, corroborando com os resultados deste estudo. De forma semelhante, barras de cereais com Lactobacillus acidophilus e Bifidobacterium animalis subsp. lactis microencapsulados por spray chilling não apresentaram diferença significativa quanto às amostras sem probiótico, inferindo que a presença dos micro-organismos não afetou sensorialmente o produto (BAMPI et al., 2016).

Na Tabela 4, encontra-se o índice de aceitabilidade das barras de cereais controle, probiótica e comercial. Todos os atributos apresentaram índice (IA) superior a $70 \%$, caracterizando-se como sensorialmente aceitáveis (DUTCOSKY, 2013). Sema-Cock et al. (2015) desenvolveram barra de cereais contendo a bactéria láctica Weissella confusa e o índice de aceitabilidade foi superior a 70\% apenas no parâmetro 'aroma'.

A amostra controle obteve maior intenção de compra, em que $61,4 \%$ declararam que certamente comprariam (nota 5) o produto, seguida da barra de cereais probiótica $(37,1 \%)$ e da barra de cereais comercial (35,3\%) (Figura 1).

Tabela 2. Resultado da análise microbiológica das barras de cereais inoculadas com a levedura probiótica após três dias de armazenamento.

\begin{tabular}{lcc}
\multicolumn{1}{c}{ Amostra } & $\begin{array}{c}\text { Coliformes } \\
\mathbf{4 5} \mathbf{C ~ N M P . g}^{-1}\end{array}$ & $\begin{array}{c}\text { Salmonella sp. } \\
\text { (Aus./ Pres.) }\end{array}$ \\
\hline Barra de cereais & $<3$ & Ausência \\
Legislação & $10^{2}$ & Ausência \\
\hline
\end{tabular}

Tabela 3. Médias das notas atribuídas pelos julgadores na análise sensorial das barras de cereais.

\begin{tabular}{lcccc} 
Amostras & Aparência & Aroma & Textura & Sabor \\
Controle & $8,0 \pm 0,97^{\mathrm{a}}$ & $7,7 \pm 1,22^{\mathrm{a}}$ & $7,8 \pm 1,13^{\mathrm{a}}$ & $7,6 \pm 1,47^{\mathrm{a}}$ \\
Probiótica & $7,6 \pm 1,35^{\mathrm{a}}$ & $7,4 \pm 1,40^{\mathrm{a}}$ & $7,7 \pm 1,20^{\mathrm{a}}$ & $7,4 \pm 1,60^{\mathrm{a}}$ \\
Comercial & $7,6 \pm 1,31^{\mathrm{a}}$ & $7,2 \pm 1,53^{\mathrm{a}}$ & $7,8 \pm 1,19^{\mathrm{a}}$ & $7,1 \pm 1,78^{\mathrm{a}}$ \\
\hline
\end{tabular}

Médias seguidas de letras iguais na coluna não diferem estatisticamente entre si pelo teste de Tukey a $5 \%$ de probabilidade.

Tabela 4. Índice de aceitabilidade das barras de cereais.

\begin{tabular}{lcccc}
\multirow{2}{*}{ Amostras } & \multicolumn{4}{c}{ Índice de aceitabilidade (\%) } \\
\cline { 2 - 5 } & Aparência & Aroma & Textura & Sabor \\
Controle & 89,1 & 86,1 & 87,2 & 80,0 \\
Probiótica & 84,4 & 82,3 & 85,6 & 82,3 \\
Comercial & 84,4 & 80,4 & 86,7 & 79,4 \\
\hline
\end{tabular}


Avaliação da aplicabilidade de uma cepa probiótica de Saccharomyces cerevisiae em barras de cereais Baliza, D. D. M. S. et al.

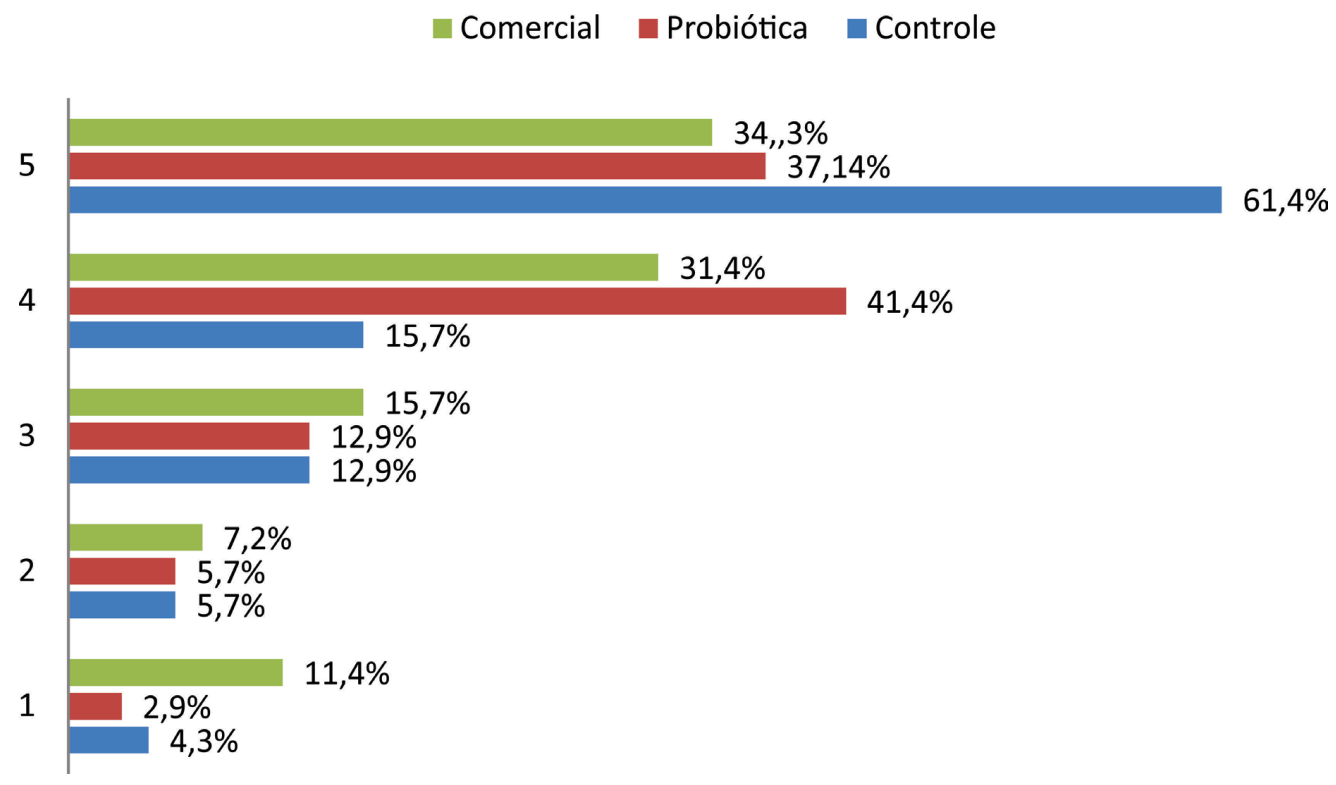

Figura 1. Porcentagem das notas atribuídas à intenção de compra das barras de cereais.

Quanto ao segundo item significativo da escala (nota 4), 41,4\% declararam que talvez comprariam a barra de cereais probiótica.

As barras de cereais comerciais disponíveis no mercado geralmente utilizam chocolate ao leite como cobertura nos cereais. Gámbaro e Ellis (2012) identificaram, em sua pesquisa, uma tendência do consumidor em associar o chocolate escuro (meio amargo ou amargo) a um alimento mais saudável, quando comparado ao chocolate ao leite e o branco. Possivelmente, o tipo de chocolate utilizado nesta pesquisa influenciou a preferência pelas barras de cereais controle e probiótica, às quais o chocolate utilizado foi do tipo escuro (53\% cacau). Note-se que a amostra controle foi mais beneficiada, por não ter sido adicionada de outros ingredientes, estando o chocolate em sua forma pura.

\section{Conclusões}

A levedura probiótica Saccharomyces cerevisiae UFMG 905 aplicada à camada de chocolate das barras de cereais não ocasiona alterações físicas e químicas indesejáveis, além de não afetar os atributos sensoriais avaliados (aparência, aroma, textura e sabor). No entanto, nesta matriz alimentícia, as células microbianas vivas não ultrapassaram 45 dias e, por isso, novos estudos devem ser realizados com a finalidade de ampliar o tempo de prateleira do produto.

\section{Agradecimentos}

Os autores agradecem a C. Martins Coelho pelo apoio técnico recebido. Este estudo foi apoiado pela CAPES (Coordenação de Aperfeiçoamento de Pessoal de Nível Superior) (AUXPE-PRO-AMAZONIA-3312/2013 / processo n. ${ }^{\circ}$ 23038.010315/2013-66).

\section{Referências}

BAMPI, G.; BACKES, G. T.; CANSIAN, R. L.; MATOS, F. E.; ANSOLIN, I. M. A.; POLETO, B. C.; COREZZOLLA, L. R.; FAVARO-TRINDADE, C. S. Spray Chilling microencapsulation of Lactobacillus acidophilus and Bifidobacterium animalis subsp. lactis and its use in the preparation of savory probiotic cereal bars. Food and Bioprocess Technology, v. 9, n. 8, p. 1422-1428, 2016. http://dx.doi.org/10.1007/s11947-016-1724-z.

BASTOS, G. A.; PAULO, E. M.; CHIARADIA, A. C. N. Acceptability of potentially probiotic cereal bars. Brazilian Journal of Food Technology, v. 17, n. 2, p. 113-120, 2014. http://dx.doi. org/10.1590/bjtt.2014.012.

BORTHAKUR, A.; GILL, R. K.; TYAGI, S.; KOUTSOURIS, A.; ALREFAI, W. A.; HECHT, G. A.; RAMASWAMY, K.; DUDEJA, P. $\mathrm{K}$. The probiotic Lactobacillus acidophilus stimulates chloride/ hydroxyl exchange activity in human intestinal epithelial cells. The Journal of Nutrition, v. 138, n. 7, p. 1355-1359, 2008. http:// dx.doi.org/10.1093/jn/138.7.1355. PMid:18567760.

BOTELHO, P. B.; GALASSO, M.; DIAS, V.; MANDRIOLI, M.; LOBATO, L. P.; RODRIGUEZ-ESTRADA, M. T.; CASTRO, I. A. Oxidative stability of functional phytosterol-enriched dark chocolate. Lebensmittel-Wissenschaft + Technologie, v. 55, n. 2, p. 444-451, 2014. http://dx.doi.org/10.1016/j.Iwt.2013.09.002.

BRASIL. Ministério da Saúde. Agência Nacional de Vigilância Sanitária - ANVISA. Resolução RDC n 12 , de 2 de janeiro de 2001. Regulamento Técnico sobre os padrões microbiológicos para alimentos. Diário Oficial [da] República Federativa do Brasil, Brasília, DF, 2001. Seção 1.

BRASIL. Ministério da Saúde. Agência Nacional de Vigilância Sanitária - ANVISA. Resolução RDC n 360, de 23 de dezembro de 2003. Regulamento técnico sobre rotulagem nutricional de 
Avaliação da aplicabilidade de uma cepa probiótica de Saccharomyces cerevisiae em barras de cereais

Baliza, D. D. M. S. et al.

alimentos embalados. Diário Oficial [da] República Federativa do Brasil, Brasília, DF, 2003.

BRASIL. Ministério da Saúde. Agência Nacional de Vigilância Sanitária - ANVISA. Resolução RDC n² 263, de 23 de setembro de 2005. Regulamento técnico para produtos de cereais, amidos, farinhas e farelos. Diário Oficial [da] República Federativa do Brasil, Brasília, DF, 2005.

BRASIL. Ministério da Saúde. Agência Nacional de Vigilância Sanitária - ANVISA. Alimentos com alegações de propriedades funcionais e/ou de saúde, novos alimentos/ingredientes, substâncias bioativas e probióticos: lista de alegações de propriedade funcional aprovadas. Brasília, DF: ANVISA, 2008.

BRUDZYNSKI, K. Effect of hydrogen peroxide on antibacterial activities of Canadian honeys. Canadian Journal of Microbiology, v. 52, n. 12, p. 1228-1237, 2007. http://dx.doi.org/10.1139/ w06-086. PMid:17473892.

CARLSON, M. Glucose repression in yeast. Current Opinion in Microbiology, v. 2, n. 2, p. 202-207, 1999. http://dx.doi. org/10.1016/S1369-5274(99)80035-6. PMid:10322167.

CHEN, L. S.; MA, Y.; MAUBOIS, J. L.; CHEN, L. J.; LIU, Q. H.; GUO, J. P. Identification of raw milk yeasts and selection for some antioxidant properties specific. International Journal of Dairy Technology, v. 63, n. 1, p. 47-54, 2010. http://dx.doi. org/10.1111/j.1471-0307.2009.00548.x.

CIRIELLO, C. J.; LACHANCE, M. A. Yeastcompare Copyright ${ }^{\circledR}$ 1999-2001. London: University of Western Ontario, 2001.

COOK, M. T.; TZORTZIS, G.; CHARALAMPOPOULOS, D.; KHUTORYANSKIY, V. V. Microencapsulation of probiotics for gastrointestinal delivery. Journal of Controlled Release, v. 162, n. 1, p. 56-67, 2012. http://dx.doi.org/10.1016/j.jconrel.2012.06.003. PMid:22698940

DE PRISCO, A.; MAURIELLO, G. Probiotication of foods: a focus on microencapsulation tool. Trends in Food Science \& Technology, v. 48, p. 27-39, 2016. http://dx.doi.org/10.1016/j. tifs.2015.11.009.

DE VRESE, M.; STEGELMANN, A.; RICHTER, B.; FENSELAU, S.; LAUE, C.; SCHREZENMEIR, J. Probiotics - compensation for lactase insufficiency. The American Journal of Clinical Nutrition, v. 73 , n. 2, p. 421-429, 2001. Supplement. http:// dx.doi.org/10.1093/ajcn/73.2.421s. PMid:11157352.

DUTCOSKY, S. D. Análise sensorial de alimentos. 4. ed. Curitiba: Champagnat, 2013. 536 p.

GÁMBARO, A.; ELLIS, A. C. Exploring consumir perception about the different types of chocolate. Brazilian Journal of Food Technology, v. 5, n. 4, p. 317-324, 2012.

GANCEDO, J. M.; MAZON, M. J.; GANCEDO, C. Kinetic differences between two interconvertible forms of fructose-1,6bisphosphatase from Saccharomyces cerevisiae. Archives of
Biochemistry and Biophysics, v. 218, n. 2, p. 478-482, 1982. http://dx.doi.org/10.1016/0003-9861(82)90370-8. PMid:6297398.

GAWKOWSKI, D.; CHIKINDAS, M. L. Non-dairy probiotic beverages: the next step into human health. Beneficial Microbes, v. $4, \mathrm{n}$. 2, p. 127-142, 2013. http://dx.doi.org/10.3920/BM2012.0030. PMid:23271064.

GUIMARÃES, M. M.; SILVA, M. S. Qualidade nutricional e aceitabilidade de barras e cereais adicionadas de frutos de murici-passa. Revista do Instituto Adolfo Lutz, v. 68, n. 3, p. 426-433, 2009.

INSTITUTO ADOLFO LUTZ - IAL. Métodos físico-químicos para análise de alimentos. 4. ed. São Paulo: IAL, 2008. 1020 p.

KABEERDOSS, J.; DEVI, R. S.;MARY, R. R.; PRABHAVATHI, D.; VIDYA, R.; MECHENRO, J.; MAHENDRI, N. V.; PUGAZHENDHI, S.; RAMAKRISHNA, B. S. Effect of yoghurt containing Bifidobacterium lactis $\mathrm{Bb} 12^{\circledR}$ on faecal excretion of secretory immunoglobulin $\mathrm{A}$ and human beta-defensin 2 in healthy adult volunteers. Nutrition Journal, v. 10, p. 138, 2011. http://dx.doi.org/10.1186/14752891-10-138. PMID: 22196482

KENNY, M.; SMIDT, H.; MENGHERI, E.; MILLER, B. Probiotics - do they have a role in the pig industry? Animal, v. 5, n. 3, p. 462-470, 2011. http://dx.doi.org/10.1017/S175173111000193X. PMid:22445413

KOVACS, D. J.; BERK, T. Recurrent Clostridium difficile associated diarrhea and colitis treated with Saccharomyces cerevisiae (Baker's yeast) in combination with antibiotic therapy: a case report. The Journal of the American Board of Family Practice, v. 13, n. 2, p. 138-140, 2000. http://dx.doi.org/10.3122/1557262513-2-138. PMid:10764197

KURTZMAN, C. P.; FELL, J. W. The yeasts: a taxonomic study. 4. ed. Amsterdam: Elsevier Science Publishers, 1998. 1076 p.

LAU, H. H.; MURNEY, R.; YAKOVLEV, N. L.; NOVOSELOVA, M. V.; LIM, S. H.; ROY, N.; SINGH, H.; SUKHORUKOV, G. B.; HAIGH, B.; KIRYUKHIN, M. V. Protein-tannic acid multilayer films: a multifunctional material for microencapsulation of food-derived bioactives. Journal of Colloid and Interface Science, v. 505, p. 332-340, 2017. http://dx.doi.org/10.1016/j.jcis.2017.06.001. PMid:28601742.

POSSEMIERS, S.; MARZORATI, M.; VERSTRAETE, W.; VAN DE WIELE, T. Bacteria and chocolate: a successful combination for probiotic delivery. International Journal of Food Microbiology, v. 141, n. 1-2, p. 97-103, 2010. http://dx.doi.org/10.1016/j. ijfoodmicro.2010.03.008. PMid:20452073.

RAO, Y.; LINGAMNENI, B.; REDDY, D. Probiotics in oral health - a review. Journal of the New Jersey Dental Association, v. 83, n. 2, p. 28-32, 2012. PMid:22866427.

RAUD, C. Os alimentos funcionais: a nova fronteira da indústria alimentar, análise das estratégias da Danone e da Nestlé no mercado brasileiro de iogurtes. Revista de Sociologia e Politica, v. 16, n. 31, p. 85-100, 2008. http://dx.doi.org/10.1590/S010444782008000200008. 
Avaliação da aplicabilidade de uma cepa probiótica de Saccharomyces cerevisiae em barras de cereais

Baliza, D. D. M. S. et al.

RAYMOND, Y.; CHAMPAGNE, C. P. The use of flow cytrometry to accurately ascertain total and viable counts of Lactobacillus rhamnosus in chocolate. Food Microbiology, v. 46, p. 176-183, 2015. http://dx.doi.org/10.1016/j.fm.2014.07.002. PMid:25475282.

SÁ, C. B. C. Caracterização de linhagens de Saccharomyces cerevisiae e Zymomonas mobilis para aplicação na produção de bioetanol. 2012. 92 f. Dissertação (Mestrado em Biotecnologia Industrial)-Centro de Ciências Biológicas, Universidade Federal de Pernambuco, Recife, 2012.

SEMA-COCK, L.; ANGULO-LÓPEZ, J. E.; AYALA-APONTE, A. A. Barras de cereal como matriz sólida para la incorporación de microorganismos probióticos. Información Tecnológica, v. 26, n. 2, p. 29-40, 2015. http://dx.doi.org/10.4067/S071807642015000200005.

SHORI, A. B. The potential applications of probiotics on dairy and non-dairy foods and their viability during storage. Biocatalysis and Agricultural Biotechnology, v. 4, n. 4, p. 423-431, 2015. http://dx.doi.org/10.1016/j.bcab.2015.09.010.

SILVA, N.; JUNQUEIRA, V. C. A.; SILVEIRA, N. F. A.; TANIWAKI, M. H.; SANTOS, R. F. S.; GOMES, R. A. A. Manual de métodos de análise microbiológica de alimentos e água. 4. ed. São Paulo: Varela, 2010. 624 p.

TEIXEIRA, E.; MEINERT, E.; BARBETTA, P. A. Análise sensorial dos alimentos. Florianópolis: UFSC, 1987.182 p.
TOURNADE, S.; AYMES, F.; RENIERO, R. WO 2005/089560 Shelf stable product with living microorganisms. Genebra: World Intellectual Property Organization, 2005.

TRIPATHI, S. K.; GIRI, M. K. Probiotic functional foods: survival of probiotics during processing and storage. Journal of Functional Foods, v. 9, p. 225-241, 2014. http://dx.doi.org/10.1016/j. jff.2014.04.030.

VANDENPLAS, Y.; HUYS, G.; DAUBE, G. Probiotics: an update. Jornal de Pediatria, v. 91, n. 1, p. 6-21, 2015. http://dx.doi. org/10.1016/j.jped.2014.08.005. PMid:25458874.

VIEIRA, A. T.; TEIXEIRA, M. M.; MARTINS, F. S. The role of probiotics and prebiotics in inducing gut immunity. Frontiers in Immunology, v. 4, p. 445, 2013. http://dx.doi.org/10.3389/ fimmu.2013.00445. PMid:24376446.

WORLD GASTROENTEROLOGY ORGANISATION - WGO. Guia prático: probióticos e prebióticos. USA: WGO, 2008. 29 p. (Diretrizes Mundiais da Organização Mundial de Gastroenterologia).

YARROW, D. Methods for the isolation, maintenance, classification and identification of yeasts. In: KURTZMAN, C. P.; FELL, J. W. The yeasts: a taxonomic study. 4. ed. Amsterdam: Elsevier Science Publishers, 1998. p. 77-100. http://dx.doi.org/10.1016/ B978-044481312-1/50014-9. 